\title{
Laparoscopic Approach to a Rare Cause of Ureteropelvic Junction Obstruction in a Child: Ureteral Polyp
}

\author{
Mehmet Surhan Arda ${ }^{1}$ Huseyin Ilhan ${ }^{1}$ Taylan Kara ${ }^{2}$ Deniz Arık ${ }^{3}$ Baran Tokar ${ }^{1}$ \\ ${ }^{1}$ Department of Pediatric Surgery, Eskisehir Osmangazi University \\ Address for correspondence Assistant Professor Mehmet Surhan \\ Medical School, Eskisehir, Turkey \\ 2 Department of Radiology, Eskisehir Osmangazi University Medical \\ Arda, Department of Pediatric Surgery, Eskisehir Osmangazi University \\ Medical School, Meselik Campus, Eskisehir 26480, Turkey \\ School, Eskisehir, Turkey \\ (e-mail: msarda@ogu.edu.tr; ardasur@gmail.com).
}

${ }^{3}$ Department of Pathology, Eskisehir Osmangazi University Medical

School, Eskisehir, Turkey

Eur J Pediatr Surg Rep 2015;3:78-81.
Abstract
Keywords
- laparoscopy
- polyp
- ureter
- fibroepithelial

Fibroepithelial polyps are a rare underlying reason of ureteropelvic junction obstruction. In the past, open surgery was the only option. However, due to development of minimal invasive technics, treatment alternatives have been changed. Resection by laparoscopy or endoscopy, laser fulguration and/or percutaneous resection are recommended in children and adults. Here, we present a 10 -year-old boy with severe left hydronephrosis due to fibroepithelial polyp close to the ureteropelvic junction and our laparoscopic approach.

\section{New Insights and the Importance for the Pediatric Surgeon}

Pediatric surgery is a specialty that has its own characteristics owing to relevance of congenital anomalies. Time to time, it is hard to estimate the real anomaly although advanced diagnostic tools are in use, as was in our case. And to me, a pediatric surgeon should be always alert, for concomitant pathologies, in any anomaly. Ureteral polyp is a rare pathology that should be in mind during pyeloplasty. Besides open access, both endoscopic or laparoscopic approaches should be in practice of surgeon, for being minimally invasive.

\section{Introduction}

Ureteropelvic junction obstruction (UPJO) in children most commonly occurs due to adynamic segment of ureter. Ureteral polyp is another rare cause of UPJO. Previously, ureteral polyp causing UPJO in children has been reported in as low as $0.5 \%$ of pyeloplasties in children. ${ }^{1}$ However, in recent studies the incidence reported was around $5 \%{ }^{2-5}$ As Li et al mentioned in their report, authors are unsure on whether it is due to more careful patient data documentation or it is about the increase of incidence. $^{5}$

received

January 30, 2015

accepted after revision

April 30, 2015

published online

October 7, 2015
Fibroepithelial polyps are more common in boys than girls. ${ }^{1-5}$ It is predominant at the left side in up to $70 \%$ of the patients. ${ }^{1,6,7}$ Moreover, bilateral cases were reported as well. ${ }^{8}$ Even if many phenotypes of fibroepithelial polyp (FEP) were defined, there is no consensus on etiology such as chronic irritation, infections, hormonal imbalance, allergy, or developmental defects. ${ }^{9,10}$

Hydronephrosis with ureteral polyp requires surgical treatment, due to the risk of malignity ${ }^{1,11}$ and obstruction. Open surgery was the only option in the past. However,

\footnotetext{
(c) 2016 Georg Thieme Verlag KG Stuttgart · New York
} 
minimally invasive techniques are currently very popular. Excision of the polyp can be performed by laparoscopy, retroperitoneoscopy, transurethral ureteroscopy, or percutaneous access. ${ }^{12-17}$ Overall, Kojima et al described performing endoscopy via a working port while laparoscopic exploration. ${ }^{4}$

In this case report, we present laparoscopic technique in a patient who had ureteral polyp close to the left UPJ.

\section{Case Report}

A-10-year old boy was admitted at our pediatric emergency department with complaints of abdominal pain and vomiting. In his medical history, he had episodes of abdominal pain without hematuria or urinary tract infection. He had mild hydronephrosis on ultrasound since the past 4 years. The abdominal pain was located on the left upper abdomen and lumbar region. Although previous ultrasound reports revealed only mild hydronephrosis, the last one showed hydronephrosis related to a polyploid lesion, which was located near UPJ and protruding into the proximal left ureter (-Fig. 1). A ${ }^{99 \mathrm{~m}} \mathrm{Tc}$ diethylenetriamine pentaacetic acid (DTPA) renography revealed nonobstructive hydronephrosis with late drainage after diuretic injection. Laparoscopic excision of the polyp was planned.

\section{Surgical Technique}

The patient was placed in supine semilateral position on the operating table. Umbilical $10 \mathrm{~mm}$ optic port (10 $\mathrm{mm}$ reusble port, Karl Storz GmbH \& Co. KG) and two $5 \mathrm{~mm}$ (disposable) working ports, one on the epigastric region and the other on the left lower quadrant were introduced. Pneumoperitoneum was created at a pressure of $13 \mathrm{~mm} \mathrm{Hg}$ with the flow of $3.5 \mathrm{~L} /$ min. Transmesocolic laparoscopic exploration showed a protruding mass on UPJ and hydronephrosis (-Figs. 2 and 3 ). Following the transmesocolic dissection of UPJ, a stay suture passing through the abdominal wall was placed to keep the left ureter hanging. Pelvis, close to the UPJ, was incised and a cauliflower-shaped polyp that was about $20 \mathrm{~mm}$ in diameter with a wide base protruding ( - Fig. 4 ) could be seen. Excision of the mass was performed including the regions of pelvis and ureter close to the mass ( - Fig. 5). Dismembered pyeloplasty was performed with interrupted 5-0 polydioxanone sutures

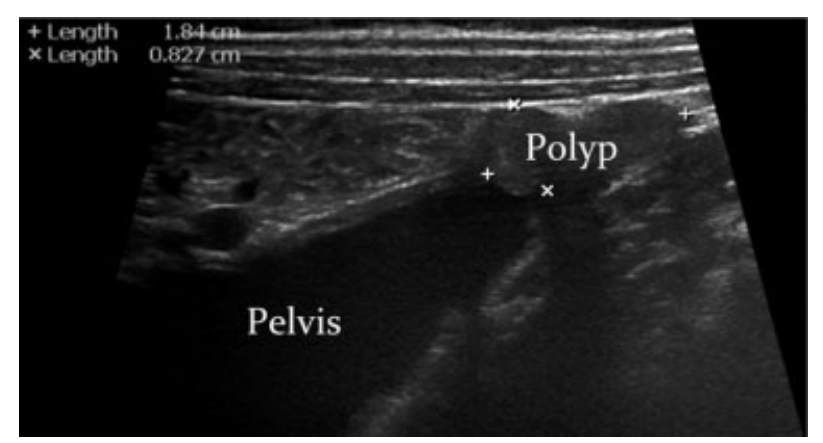

Fig. 1 USG image of ureteral polyp. USG, ultrasound.

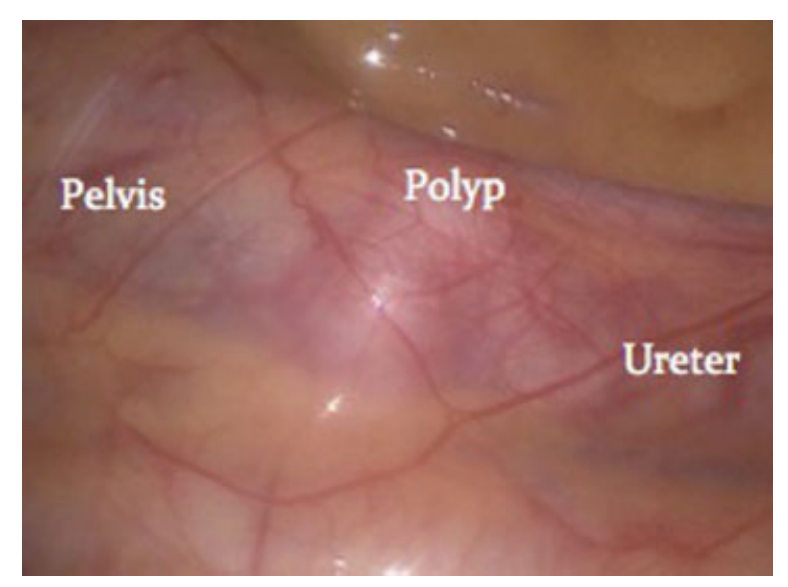

Fig. 2 Transmesocolic view of ureteral polyp during laparoscopy through retroperitoneum.

and double J stent was placed. Thereafter, mesocolic window was closed. The total operative time was 200 minutes, with an estimated operative blood loss of $20 \mathrm{~mL}$. The patient was discharged on the 3rd postoperative day. The stent was removed in the 3rd postoperative week. Pathology confirmed the mass excised as FEP. After a follow-up of 2 years, patient did well with normal DTPA renography.

\section{Discussion}

FEPs of the ureter are of mesoderm origin, rare benign tumors in children. ${ }^{18}$ They may arise in any location from renal pelvis to the urethra in the order of decreasing frequency. ${ }^{19}$ On the other hand, FEPs may have varied sizes and shapes. They might be 1 to $50 \mathrm{~mm}$ long or have shapes such as pedunculated with a smooth surface or with multiple finger-like projections. ${ }^{1,10,20,21}$ Age of the patient, structural features of polyps, and experience level of the surgeon determine treatment preferences and consequences of surgery.

However, although there are few studies, transitional cell carcinoma arising from fibroepithelial polyp and recurrence due to incomplete resection has been reported. ${ }^{11,22}$ On the other hand, Adey et al stated in 2003 that only $22 \%$ of FEPs were diagnosed preoperatively and Li et al mentioned in 2014 that none of the FEPs in their study were detected before surgery. ${ }^{1,5}$ In our case, FEP was detected after a follow-up of 4

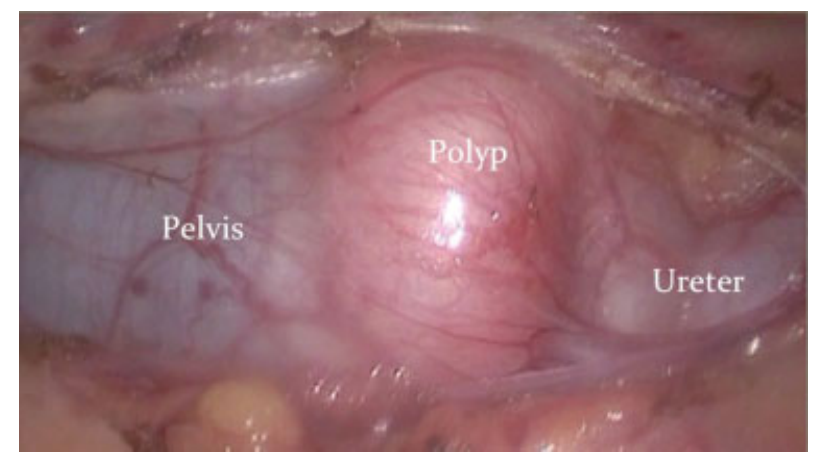

Fig. 3 Transmesocolic view of ureteral polyp after dissecting the retroperitoneum. 


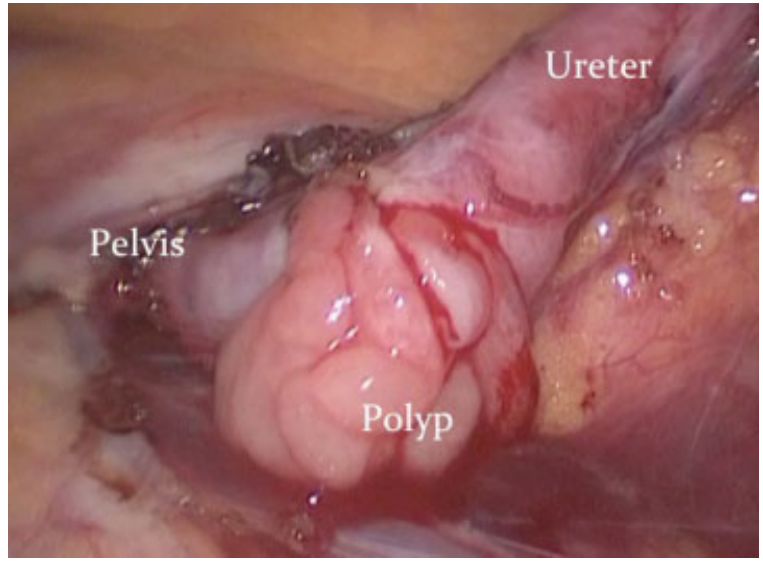

Fig. 4 Ureteral polyp protruding outside from the incision of UPJ. UPJ, ureteropelvic junction.

years. So we believe the delay in diagnosis might be due to intermittent obstruction and slow growing nature of polyp. Although malignity, recurrence, and any other associated polyp is extremely low, surgeon should ensure not to leave remnant of FEPs during excision.

In the past, open surgery was the only option, however, recently minimal invasive approaches have been recommended in children and adults..$^{4,13-15,23}$ Furthermore, several authors have described their successful experience in using holmium laser resection, percutaneous, and/or ureteroscopic approaches in the treatment of FEPs. ${ }^{13-15}$ Conversely, Sun et al figured out in their study that strictures might be cause of over vaporization and Kiel et al mentioned the risk of recurrence due to incomplete resection of tumor. ${ }^{4,15,24}$ Bartone et al speculated that resecting the polyp without base might cause obstruction and recurrence. ${ }^{25}$ On the other hand, Adey et al underlined the importance of dismembered pyeloplasty whereas polyps might have been missed, if spiral flap

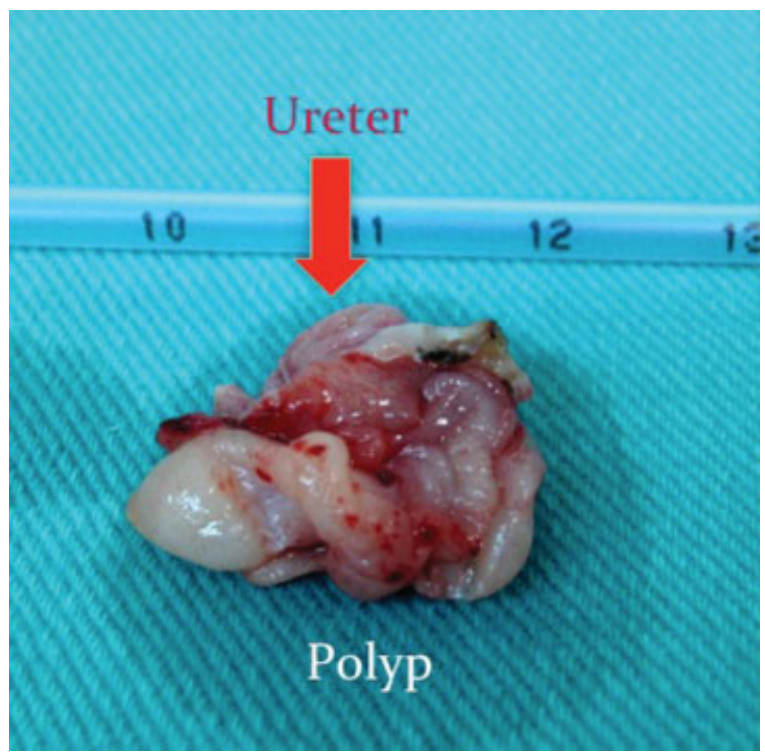

Fig. 5 Surgical margins of pathology. or Y-V pyeloplasty is performed. ${ }^{1}$ Moreover, Iwatsuki et al and Tsuzuki et al published their successful laparoscopic treatment of FEP either in child and adult patients. ${ }^{16,26}$

Since FEP was located close to UPJ, we preferred to perform laparoscopy. Laparoscopy has several advantages compared to endoscopic procedures, especially in children. It should be noted that, despite postoperative controversies of endoscopic resection or fulguration of a wide base polyp; local resection, fulguration, or pyeloplasty can be performed easily during laparoscopic approach. The overall laparoscopic exploration shows the exact location and size of the polyp, neighboring organs, and structures. Luminal mucosal evaluation with exposure of proximal and distal resection margins could be performed well with optic magnification.

There are several options for laparoscopic approach to renal pelvis and UPJ region on the left side. Depending on the patient and experience of the surgeon retroperitoneoscopy, transabdominal retrocolic or transmesocolic approaches can be performed. ${ }^{12-17}$ To our knowledge, in pediatric age group, retroperitoneoscopy and endoscopy may not provide enough surgical working space. So we suggest transabdominal transmesocolic approach and believe that exploration and surgical manipulation might be easier compared to retroperitoneoscopy or endoscopy.

\section{References}

1 Adey GS, Vargas SO, Retik AB, et al. Fibroepithelial polyps causing ureteropelvic junction obstruction in children. J Urol 2003;169(5): 1834-1836

2 Kara C, Reşorlu B, Oğuz U, Unsal A. Incidentally detected ureteral fibroepithelial polyps in children: is endoscopic treatment of them really necessary? Int Urol Nephrol 2010;42(1):1-5

3 Bian Z, Liu X, Hua Y, Liu F, Lin T, He D. Laparoscopic management of multiple ureteral polyps in children. J Urol 2011;186(4):1444-1449

4 Kojima Y, Lambert SM, Steixner BL, Laryngakis N, Casale P. Multiple metachronous fibroepithelial polyps in children. J Urol 2011; 185(3):1053-1057

5 Li R, Lightfoot M, Alsyouf M, Nicolay L, Baldwin DD, Chamberlin DA. Diagnosis and management of ureteral fibroepithelial polyps in children: A new treatment algorithm. J Pediatr Urol 2015;11(1): 22.e1-22.e6

6 Lavelle JP, Knisely AS, Bellinger MF. Benign fibroepithelial polyps causing symptomatic bilateral intermittent hydroureteronephrosis. J Urol 1997;158(2):569

7 Williams TR, Wagner BJ, Corse WR, Vestevich JC. Fibroepithelial polyps of the urinary tract. Abdom Imaging 2002;27(2):217-221

8 Romesburg JW, Stein RJ, Desai MM, Lagwinski N, Ross JH. Treatment of child with bilateral ureteropelvic junction obstruction due to fibroepithelial polyps and review of the literature. Urology 2009;73(4):929.e9-929.e11

9 Menon P, Kakkar N, Rao KL. Antenatal hydronephrosis: ureteral polyp causing ureteropelvic junction obstruction. Eur J Pediatr Surg 2004;14(5):345-347

10 Banner MP, Pollack HM. Fibrous ureteral polyps. Radiology 1979; 130(1):73-76

11 Zervas A, Rassidakis G, Nakopoulou L, Mitropoulos D, Dimopoulos C. Transitional cell carcinoma arising from a fibroepithelial ureteral polyp in a patient with duplicated upper urinary tract. J Urol 1997;157(6):2252-2253

12 Segawa N, Abe H, Nishida T, Katsuoka Y. Ureteral polyp occurring as renal dysfunction with contralateral ureteral calculi: a case report [in Japanese]. Hinyokika Kiyo 2005;51(7):451-453 
13 Lam JS, Bingham JB, Gupta M. Endoscopic treatment of fibroepithelial polyps of the renal pelvis and ureter. Urology 2003;62(5): 810-813

14 Yagi S, Kawano Y, Gotanda T, et al. Endoscopic treatment of a long fibroepithelial ureteral polyp. Int J Urol 2001;8(8):467-469

15 Sun Y, Xu C, Wen X, et al. Is endoscopic management suitable for long ureteral fibroepithelial polyps? J Endourol 2008;22(7): 1459-1462

16 Iwatsuki S, Kojima Y, Mizuno K, Tozawa K, Kohri K, Hayashi Y. Laparoscopic management for fibroepithelial polyp causing ureteropelvic junction obstruction in a child. Urology 2010;76(1): 146-148

17 Hasegawa Y, Mita K, Ueki T, et al. Retroperitoneoscopic treatment of ureteral invagination caused by a long fibroepithelial polyp protruding into the bladder: report of a case. Surg Today 2011; 41(8):1117-1121

18 Zeman L, Dusek M, Lisy J, et al. Multiple fibroepithelial polyps of the upper ureter in a 17-year-old boy-case report and review of the literature. Eur J Pediatr Surg 2004;14(5):358-361
19 Musselman P, Kay R. The spectrum of urinary tract fibroepithelial polyps in children. J Urol 1986;136(2):476-477

20 Güp A. Benign mesodermal polyp in childhood. J Urol 1975; 114(4):619-620

21 Psihramis KE, Hartwick W. Ureteral fibroepithelial polyp with positive urinary cytology. Urology 1993;41(4):387-391

22 Ruíz-López MJ, Ramírez-Garrido F, Nogueras-Ocaña M, MuñozHoyos A, Martín A. Recurrent ureteric fibroepithelial polyp in a child. Eur J Pediatr 2004;163(2):124-125

23 Faerber GJ, Ahmed MM, Marcovich R, Crisco CP, Belville WD. Contemporary diagnosis and treatment of fibroepithelial ureteral polyp. J Endourol 1997;11(5):349-351

24 Kiel H, Ullrich T, Roessler W, Wieland WF, Knuechel-Clarke R. Benign ureteral tumors. Four case reports and a review of the literature. Urol Int 1999;63(3):201-205

25 Bartone FF, Johansson SL, Markin RJ, Imray TJ. Bilateral fibroepithelial polyps of ureter in a child. Urology 1990;35(6):519-522

26 Tsuzuki T, Epstein JI. Fibroepithelial polyp of the lower urinary tract in adults. Am J Surg Pathol 2005;29(4):460-466 